\section{Toxicity of doxorubicin and methotrexate in osteogenic sarcoma}

Recent reports have held out hope that chemotherapy with doxorubicin and methotrexate can prevent the development of metastases when given immediately after primary treatment of osteogenic sarcoma. ${ }^{12}$ Nevertheless, it is uncertain how these drugs should be used together to obtain maximum therapeutic advantage and differing schedules are being used in current clinical trials. Our patient illustrates the importance of drug sequence in treatment and that a small variation in this can result in an appreciable difference in biological effect.

\section{Case report}

The patient, an 18-year-old girl, suffered from metastatic osteogenic sarcoma. Courses of chemotherapy were given at monthly intervals (figure). First course-Doxorubicin, $60 \mathrm{mg} / \mathrm{m}^{2}$, preceded a 24 -hour infusion of methotrexate, $200 \mathrm{mg} / \mathrm{m}^{2}, 10^{\circ}{ }_{0}$ of the dose being given over the first ten minutes. Six doses of folinic acid, $20 \mathrm{mg} / \mathrm{m}^{2}$ intramuscularly, at six-hourly intervals were started six hours after the methotrexate had finished.

Second course-Vincristine $1.4 \mathrm{mg} / \mathrm{m}^{2}$ was given 30 minutes before the methotrexate. Doxorubicin, $73 \mathrm{mg} / \mathrm{m}^{2}$, followed six hours after the methotrexate at the time of the first dose of folinic acid.

Third course-Doses were reduced to doxorubicin, $43 \mathrm{mg} / \mathrm{m}^{2}$, followed by methotrexate $120 \mathrm{mg} / \mathrm{m}^{2}$ and folinic acid $12 \mathrm{mg} / \mathrm{m}^{2}$.

Fourth course-Dosage was as above, but vincristine preceded the methotrexate and doxorubicin was given six hours after the infusion with the first dose of folinic acid.

Fifth course-Vincristine was again given and the doxorubicin dose was increased to $60 \mathrm{mg} / \mathrm{m}^{2}$, given before the methotrexate infusion of $200 \mathrm{mg} / \mathrm{m}^{2}$. The patient's tumour showed a satisfactory response but there was a considerable variation in the toxicity of the treatment courses. The first, third and fifth courses were followed by little oropharyngitis and only mild neutropenia two weeks later (figure). When doxorubicin followed methotrexate however (courses two and four) there was definite neutropenia. Also after the second course a severe oropharyngitis required tube feeding for nine days. This side effect was only slightly less after the fourth course. There was no biochemical evidence of hepatic or renal disturbance either before or after each treatment course.

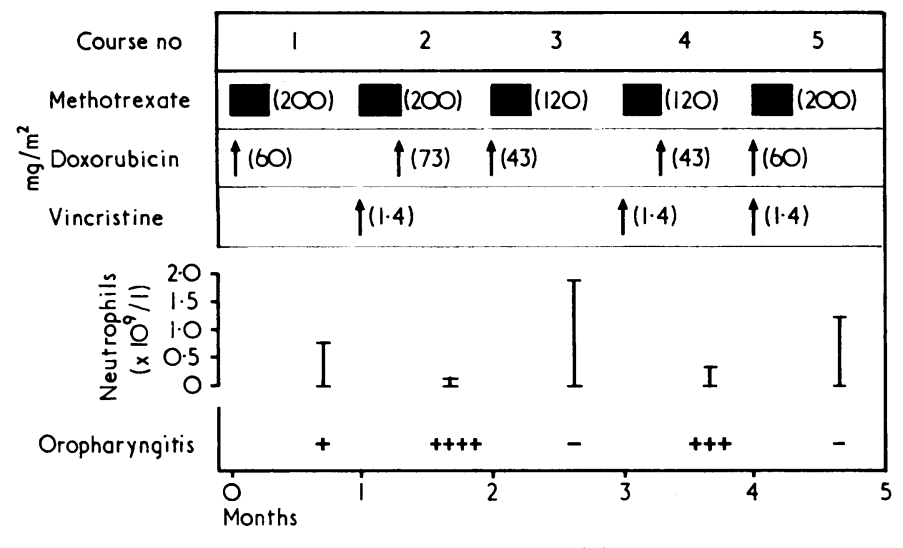

Treatment courses and toxicity.

\section{Discussion}

Delaying the dose of doxorubicin by only 30 hours resulted in a definite increase in toxicity in this patient, indicating an intimate relationship between biological effect and the scheduling of methotrexate and doxorubicin. We found no evidence of hepatic dysfunction to suggest that prior administration of methotrexate impaired the metabolism of doxorubicin. Furthermore, substantial reduction in dosage only slightly reduced toxicity.

Membrane transport of methotrexate is known to be enhanced by some drugs. ${ }^{3}$ Such a mechanism seems unlikely to account for increased toxicity when doxorubicin is given after the methotrexate and at a time of folinic acid administration. Nevertheless, a similar effect might result if doxorubicin interfered with folinic acid transport. A further possibility is that which prompted us to alter the treatment schedule. Methotrexate, being most cytotoxic against cells in the DNA synthetic phase, might be more active if it were not preceded by doxorubicin-which could perhaps prevent cells proceeding to this susceptible phase. In the mouse L-asparaginase has such a property and may indeed be used to protect against the cytotoxic effect of methotrexate. ${ }^{4}$

Although the explanation for our observations is uncertain, clearly the scheduling of these drugs is important in the design of clinical trials. Moreover, further study of the pharmokinetic mechanism of this drug interaction may lead to more effective combined therapy.

${ }^{1} \mathrm{Jaffe}, \mathrm{N}$, et al, New England Fournal of Medicine, 1974, 291, 994.

2 Cortes, E P, et al, New England fournal of Medicine, 1974, 291, 998.

${ }^{3}$ Zager, R F, Frisby, S A, and Oliverio, V T, Cancer Research, 1973, 33, 1670

${ }^{4}$ Capizzi, R L, Summers, W P, and Bertino, J R, Annals of the New York Academy of Sciences, 1971, 186, 302.

The laboratories, Belfast City Hospital, Belfast BT9 7AD

J H ROBERTSON, MRCP, MRCPATH, consultant pathologist MARY J HOLLINGER, MB, registrar

Mid-Ulster Hospital, Magherafelt

C WILSON, MRCP, consultant physician

\section{Decreased sebum excretion in chronic renal failure}

There is good evidence for the existence of a sebotrophic hormone. ${ }^{1}$ The inhibitory control of this hormone and the occurrence of seborrhoea in various states ${ }^{1}$ suggested that the hormone might be an $\mathrm{MSH}$ in man, as it appears to be in the rat. ${ }^{2}$ We have found an increase in immunoreactive " $\beta-M S H$ " in the plasma of patients with chronic renal failure $(\mathrm{CRF})^{2}$ and have now measured the sebum excretion rate (SER) in these patients. None of the patients was receiving drugs known to affect the SER apart from two of the men, who were being treated with testosterone esters in an oily base (Sustanon), $250 \mathrm{mg}$ weekly, for anaemia.

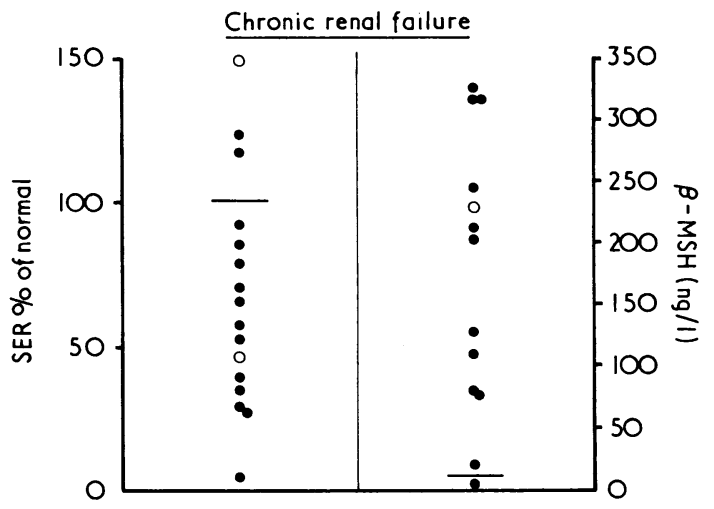

Sebum excretion rate and plasma immunoreactive " $\beta$-MSH" in patients with chronic renal failure. Horizontal line marks normal mean. Two patients who were receiving androgen are marked with open circles.

\section{Patients, methods, and results}

Sixteen patients (seven female, nine male) with CRF were studied. One was receiving weekly peritoneal dialysis (48 hours/week), eight were on regular haemodialysis (three $\times 6-8$ hours/week), and seven who had serum creatinine concentrations between 548 and $1229 \mu \mathrm{mol} / 1(6.2$ and $13.9 \mathrm{mg} /$ $100 \mathrm{ml}$ ) were not being treated by dialysis. The SER was measured on the forehead in all 16 patients by a method modified by Cunliffe and Shuster. ${ }^{1}$ Blood was taken from 13 of the patients, immediately before dialysis in those so treated, and plasma immunoreactive " $\beta-\mathrm{MSH}$ " measured by a modification of the method of Thody and Plummer. ${ }^{3}$ The results were compared with our previously established normal range for both methods.

The mean SER in the 16 patients with CRF was decreased to $66.6 \pm$ $10.6 \% \mathrm{SE}$ of mean of the normal for comparable age and sex. This decrease is significant $(P<0.05)$ and occurred despite the considerable increase in 
plasma immunoreactive " $\beta$-MSH" (figure). The decrease in SER was greater in the females $(46.3 \pm 13.8 \%$ SE of mean) than in the males $(82.4 \pm 13.9 \%$ $\mathrm{SE}$ of mean) in whom the decrease was not significantly different from the normal $(0.1<P>0.05)$

\section{Discussion}

The decreased SER we found in CRF suggests that the hormone measured as immunoreactive " $\beta-M S H$ " is not sebotrophic in man, though the possibility that sebotrophic activity is inhibited in renal failure cannot be excluded. The melanocyte-stimulating hormone in man has been thought to be a $\beta-M S H$, but recent evidence suggests this hormone normally exists only as part of the larger lipotrophin (LPH) molecule, ${ }^{4}$ which cross reacts in the present assay of " $\beta-M S H . "$ Hence apparently LPH is not sebotrophic in man even, though ovine $\beta-\mathrm{LPH}$ is strongly sebotrophic in the rat. ${ }^{1}$ This conclusion agrees with our evidence from several different clinical states that changes in SER and immunoreactive " $\beta-M S H$ " are unrelated. The nature of the postulated sebotrophic hormone still remains to be clarified in man. Why there is a decrease in SER is uncertain. One possibility is the decrease in androgen metabolism which occurs in CRF. ${ }^{5}$ Only two of our patients were being treated with testosterone; in one the SER was increased and in the other it was low. Further studies are required to establish whether there is an impaired target organ response to androgen in CRF. It is likewise uncertain to what extent the decrease in SER contributes to the "dry" scaly skin of CRF or indeed whether this is a factor in the pruritus. Since, however, these changes may be less obvious in hypopituitarism and hypoadrenalism, despite a comparable or larger decrease in SER, ${ }^{1}$ changes in epidermal synthesis of structural lipid may also be important.

We are grateful for grants from the Medical Research Council, The Wellcome Trust, and the North of England Cancer Campaign.

1 Shuster, S, and Thody, A J, Fournal of Investigative Dermatology, 1974, $62,172$.

2 Thody, A J, and Shuster, S, fournal of Endocrinology, 1975, 64, 503.

3 Smith, A G, et al, British Medical fournal, 1975, 1, 658.

4 Scott, A P, and Lowry, P J, Biochemical fournal, 1974, 139, 593.

5 Van Kammen, E, et al, fournal of Endocrinology, 1975, 64, 49P.

University Departments of Dermatology and Medicine, Royal

Victoria Infirmary, Newcastle upon Tyne

SAM SHUSTER, PHD, FRCP, professor of dermatology

$S$ K GOOLAMALI, MRCP, senior registrar

A G SMITH, MRCP, Wellcome research fellow

A J THODY, PHD, lecturer

F ALVAREZ-UDE, LMS, research registrar

D N S KERR, MSC, FRCP, professor of medicine

\section{Carcinoma of the pancreas and acute renal failure}

Acute renal failure associated with a pancreatic carcinoma may be caused by diffuse intravascular coagulation ${ }^{1}$ or by renal tubular obstruction by mucoproteins. ${ }^{2}$ We report a patient with an unsuspected pancreatic adenocarcinoma who presented with ischaemia of her right hand and subsequently developed acute renal cortical necrosis.

\section{Case history}

A 57-year-old woman was admitted to St Peter's Hospital, Chertsey, in March 1973 with a three-day history of paraesthesiae in her right hand Twenty-four hours before admission the fingers of her right hand had become painful and cyanosed. She also complained of six weeks' vague central abdominal pain. Her right hand was ischaemic with an absent radial pulse; a loud systolic murmur was audible over the right clavicle, but there were no other abnormal physical signs. An aortogram showed stenosis of the right subclavian artery at the border of the first rib; no cervical rib was seen and a fibrous band was suspected. She was anticoagulated with heparin 10000 units six-hourly without improvement. Nine days later her radial and brachial arteries were explored and thrombus removed from the radial artery using a Fogarty's catheter. Despite improved blood flow at operation her fingers became gangrenous.

Twelve days after operation, when apart from her ischaemic fingers she seemed well, she had mild haematuria and became totally anuric until her death six days later. Treatment with warfarin had begun two days earlier and heparin had been discontinued 36 hours after starting warfarin. Investigations at the onset of anuria showed a blood urea of $11.45 \mathrm{mmol} / 1(69 \mathrm{mg} / \mathrm{dl})$ with normal electrolytes. Her haemoglobin had dropped $5.6 \mathrm{~g}$ to $8.6 \mathrm{~g} / \mathrm{dl}$ since the last estimation ten days previously. Her white count was $33.6 \times 10^{\circ} / 1$ and platelets $194 \times 10^{9} / 1$; the blood film was normal. Blood cultures were negative. Her plasma calcium was $2.38 \mathrm{mmol} / 1(9.5 \mathrm{mg} / \mathrm{dl})$ and phosphate $1.87 \mathrm{mmol} / 1(5.8 \mathrm{mg} / \mathrm{dl}$ ). Her prothrombin time was $120 \mathrm{~s}$ (control $12 \mathrm{~s}$ ). Because of the fall in haemoglobin, a grossly prolonged prothrombin time, and total anuria, a retroperitoneal haemorrhage causing bilateral ureteric obstruction was suspected, but a retrograde pyelogram showed normal appearances. A renal arteriogram showed that both renal arteries were patent but produced no nephrogram.

At necropsy her kidneys showed confluent bilateral cortical necrosis with fibrin thrombi in the afferent glomerular arterioles (fig). A scirrhous mucussecreting adenocarcinoma had replaced most of the head and body of the pancreas and had metastasised widely throughout the abdomen. Thrombi were present in the lungs, portal vein, submucosal veins of the colon (which showed patchy infarction), and in the right subclavian and brachial arteries.

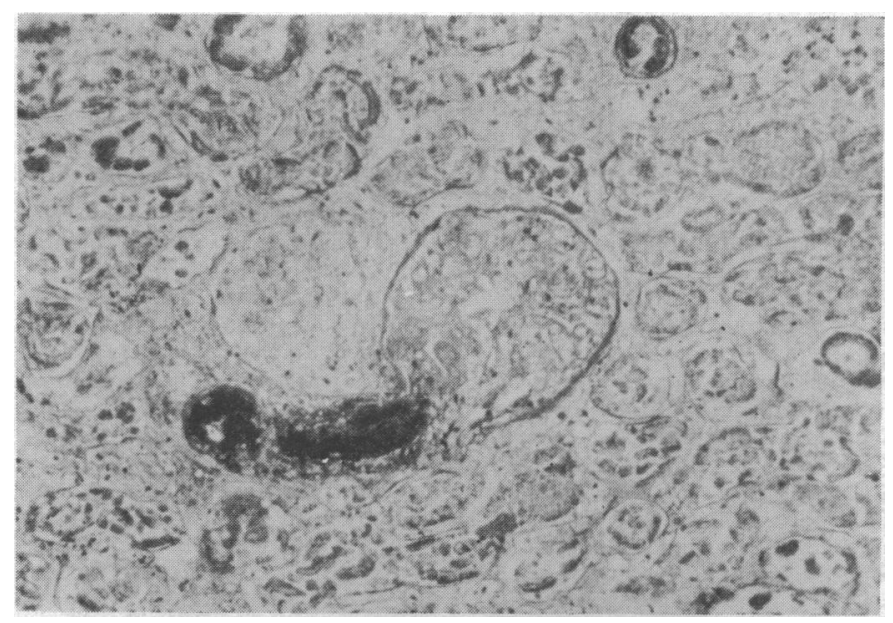

Photomicrograph of kidney showing fibrin thrombus in afferent arteriole ( $\times 125)$ stained with Mallory's phosphotungstic acid haematoxylin (PTAH).

\section{Discussion}

Cortical necrosis accounts for only $2 \%$ of cases of acute renal failure: concealed accidental haemorrhage in pregnancy is much the commonest cause, ${ }^{3}$ but it may result from any sudden, severe renal ischaemia. This patient was at no time hypotensive, nor was there any obvious change in her clinical condition at the onset of anuria. Although there was no overt bleeding apart from the one episode of haematuria (reasonably explained by renal infarction), the platelet count was never low-and the blood film was normal-she was found at necropsy to have diffuse intravascular clotting in arteries and veins, large and small. Thrombophlebitis migrans is commonly associated with pancreatic carcinoma, but it is unusual for venous and arterial thromboses to coexist. ${ }^{4}$ In this case thrombosis of a large artery was associated with predisposing subclavian artery stenosis.

In unexplained acute renal failure an unsuspected carcinoma must be considered as a possible diagnosis.

We thank Mr K W Wilkinson for permission to report this case, and Dr C F Ross for the necropsy report and microphotograph.

${ }^{1}$ McKay, D G, Disseminated Intravascular Coagulation. New York, Harper and Row, 1965.

2 Hobbs, J R, Evans, D J, and Wrong, O M, British Medical fournal, 1974, $2,87$.

${ }^{3}$ Walls, J, Schorr, W J, and Kerr, D N S, British Medical fournal, 1968, 4, 220.

${ }^{4}$ Buttercross, D, and Salatich, J, Annals of Internal Medicine, 1955, 43, 213.

St George's Hospital, London SW1

ROBERT E LORGE, MB, MRCP, medical registrar

PETER RICHARDS, MD, MRCP, consultant physician 